\title{
A Conceptual Framework for Accounting Education Research
}

\author{
Dr Audra Ong \\ University of Windsor \\ Odette School of Business \\ 401 Sunset Avenue \\ Windsor, Ontario \\ N9B 3P4, Canada \\ Email: aong@uwindsor.ca \\ Dr Roger Hussey \\ University of Windsor \\ Odette School of Business \\ 401 Sunset Avenue \\ Windsor, Ontario \\ N9B 3P4, Canada \\ Email: rhussey@uwindsor.ca
}

\begin{abstract}
There has been substantial research into different aspects of teaching accounting at the undergraduate level. However, a substantial part of the research has focussed on only one part of the process, the understanding of students. The findings of the research have improved our knowledge of the student's learning issues but have done little to illuminate the connections in the entire educational process, including such factors as lecturing styles and the quality of printed materials. This paper explains communication theory and reviews the research that has been conducted into various aspects of that theory. A conceptual framework is constructed that identifies and incorporates all the different aspects and identifies the importance of their relationships. The paper is completed with a proposal for further research based on the conceptual framework.
\end{abstract}

Keywords: Accounting education; communications theory; information transmission; research design.

\section{Introduction}

The Committee on the Application of Learning and Communication Theories to Accounting Instruction was given the responsibility "to study and report upon the applicability of learning and communication theories to accounting instruction, to provide general guidelines for developing and testing alternative approaches or methods of utilizing these concepts in the teaching of accounting subjects and to recommend ways to which the AAAcan encourage and support improvement in this area."(American Accounting Association1972).

One conclusion of the Committee was that in improving learning processes, research should encompass the structure of the classroom, methods of presentation of material, and the role of the teacher. It is extremely difficult for a single research project, unless it is carefully structured to study the entire accounting educational process. Previous research studies have selected, therefore, a specific area to investigate. Mostly, studies are conducted in one location at one point in time with one group of students and focuses on only one stage of the communication process. Although this provides depth, there is the disadvantage that our understanding of the overall process of education remains incomplete.

In this paper we address the issues by suggesting a conceptual framework that draws from several communication studies. We concentrate on accounting academics and students and build on the framework to propose the key attributes of future accounting education research. We acknowledge the contributions of previous studies but also identify their restricted view and propose a comprehensive research approach that opens up new ways of understanding and improving accounting education.

\section{The Communication Process}

There is an extensive literature addressing various aspects of teaching accounting with most studies focus on specific issues. Although these studies have enhanced our understanding of one particular aspect, they ignore the importance and relationship of other aspects. If we are to gain a fuller understanding, we need to give attention to the entire communication process. 
There have been several studies in different disciplines that have identified the structure of a communications process. Possibly the best known are Shannon and Weaver (1949),Berlo(1960) and strictly applied to accounting (Bedford and Baladouni2002). Although there are differences depending on the particular situation the authors are considering there is general agreement that the communications process involves the following stages.

A sender of information who will encode the material in a form deemed suitable for the intended recipient. The sender could be the authors of books or articles and the lecturer. The content of the information to be transmitted is decided usually by either a professional accounting body or the university or college. An individual lecturer, the sender of information to the student, may have little control on the type and nature of the information to be transmitted. The transmission of the information which may be in several ways. Later in this paper we discuss the various methods.

The recipient of the information who is the student decoding the material to understand the meaning. Feedback to the recipient which in most instances will be some form of testing the students' understanding. Most accounting research in this area has concentrated on the different methods of transmitting the information to the students and the decoding of the material by the students.

\subsection{Information transmission}

There has been a substantial growth in the transmission methods used other than by a lecturer standing in front of students. We are now in an era where the classroom presentation relies on a textbook complete with a supporting set of power point presentations and a test bank of questions. Where a course is provided entirely on-line, the lecturer and classrooms may disappear.

One study (Braun and Sellers 2012) relates to introductory accounting. A short daily quiz consisting of three easyto-grade conceptual questions was used before class. Class attendance, prior preparation and participation in discussions improved. In addition, lower failure rates occurred in semesters that incorporated a daily quiz and the use of the daily quiz had no adverse effect on course and instructor evaluations.

Another approach advocated for improving learning is writing to learn (WTL).The argument is that students learn concepts better when they write about them. Grimm (2015) describes the design and implementation of learning $\operatorname{logs}$ in an introductory financial accounting course. A survey indicated students perceived the learning $\operatorname{logs}$ as useful for promoting learning outcomes and increasing content comprehension.

$\mathrm{Du}$ (2015) examined cooperative learning as a means of increasing students' interest in a first year Principles of Accounting course. The cooperative learning approach adopted formed learning group with stable membership at the beginning of the semester. The groups were monitored and showed that although students are neutral in their interest in accounting as a subject, they agreed that cooperative learning helped to maintain interest and attention.

The move from a "talk and chalk" approach to a method that involves students more actively presents challenges. Kirstein and Kunz (2015) examined student centred learning on auditing courses in a South African university. They concluded that "non-standard" teaching practices can be implemented successfully and maintain student involvement even with large classes.

Given the variety and range of delivery methods, caution must be used in attempting comparisons, although some studies have been able to identify features that reveal the strengths and weaknesses of the different approaches. However, what may be successful in one setting may not be so in another. Lopez-Gavira and Omoteso (2013) studied accounting students' perceptions of the usefulness of Virtual Learning Environments (VLE) in two different countries. The results revealed that students from both countries found VLE tools and techniques useful for their learning, but students' perceptions of the usefulness of VLEs are strongly dependent upon their country of study with significant differences between Spanish and English students.

Perera and Richardson (2010) investigated the link between the students' use of different forms of online course provisions and tools (i.e. course materials, links and discussion forums) and examination performance. The research was conducted with students in a second-year undergraduate accounting course. The results showed that there was a positive association between the number of online files viewed by students, the number of online discussion messages posted by them, and their examination performance. There was no significant relationship between examination performance and the amount of time spent on the subject's web site, the viewing of links to web sites that were not core to the course being studied, or the passive reading of discussion messages. One conclusion that can be drawn is that online course materials can benefit students' examination performance but only if students are active in using the materials.

Blended or hybrid courses, which include features of both in-class and online courses, are becoming more common. Sargent, Borthickand Lederberg (2011) examined the use of ultra-short online videos within-class courses. Twenty-seven ultra-short videos were created for the course, three for each of nine chapters. 
The content covered a concise explanation of the main concept, their application in solving accounting problems, and a problem for students to solve. The videos did not repeat the content in the lecture. The students' usage rates were above 60 percent, although there was no course credit for viewing them. Students watching the tutorials had significantly lower course drop rates and better pass rates.

It should not be concluded that blended courses are always the best. Research by Baker (2016) was specifically on accounting for pensions. Fifty-six undergraduate accounting students with no knowledge of pension accounting were placed into one of two experimental groups. The same in class lecture on the computation of pension accounting was given to both groups. One group practiced and computed pension expense using only pencils and paper. The other group used an online homework tool. The students who performed the work by hand scored higher on a post-quiz covering pension expense and reported a higher level of confidence in their knowledge of pension expense as compared to students using the online homework tool.

\subsection{The information recipients}

The recipients of the information, the students, will have a decoding process which involves their understanding of the material. Culture and language can be factors in this process. Although some studies have looked at the impact of the "culture" of foreign students on learning, few studies focus on the impact of the culture of authors and lecturers on the encoding of material. Some aspects of this were mentioned by Ferguson, Collison, Power and Stevenson (2005 and 2010). The type of language used by authors of textbooks and other teaching materials may also shape the message. There are probably many words and phrases used by the sender group that may be unfamiliar or have a different nuance for the recipient group.

In view of the many different approaches adopted, comparison of methods should be treated with caution. We could be comparing an in-class presentation by a poor lecturer to a highly professional video presentation by a star speaker. However, studies have been conducted and raise interesting aspects.

Bunker and Harris (2014) conducted a study comparing in-class and online courses. The findings were that students from predominantly online accounting programs significantly underperform on overall CPA Exam pass rates and average CPA Exam scores compared to candidates from both AACSB-accredited business schools and traditional, non-AACSB-accredited business schools. The conclusion was that both AACSB accredited and non-AACSBaccredited business schools attract better quality students and/or better prepare their students for the CPA Exam than predominantly online accounting programs.

The above study gives two reasons for the differences in student performance. The students attending in-class courses were either better prepared or were better quality students. Morgan (2015) made a direct comparison of equivalent student selection criteria. The research compared online and in-class programmes for the certified public accountant examinations. The results for online courses had much lower average CPA pass rates than inclass courses. In addition, average 6-year graduation rates and average propensity to sit for the CPA exam after graduation are much lower in the online accounting programs.A study by Chen, Jones and Moreland (2013) adds another dimension to our knowledge. The research considered both introductory and advanced accounting courses. The conclusions were that the course level is important in assessing the effectiveness of the two different modes of delivery. In advanced courses, the outcomes examined were significantly more favourable for traditional classroom environments than for online. With introductory courses, the delivery mode was not important.

Several studies have examined student characteristics to compare in-class and online courses. Huh, Jin, Lee and Sehwan (2009) considered such characteristics as grade point average (GPA), age, commuting distance, working hours, gender and marital status. GPA was the only factor affecting performance for both online and offline students. The significant impact on performance was for the in-class students only. Specifically, male students performed better than female students (80.5 versus 70.9 ). The authors point out that students taking online courses are older, commute longer distance and work more hours than those taking in-class courses.

Watters and Robertson (2009) also observed this difference in the responses to in-class and online courses depending on the characteristics of the students. The three-way comparison was students on introductory undergraduate, upper-division undergraduate and graduate accounting courses. All course lectures were prerecorded and made available with all other course-related content. Students in the three courses could access the archived video presentations over the internet or burn the presentations to a CD or a flash memory drive thus allowing students to view the digital videos at any time and as many times as desired.

All the graduate course students in this study considered that the online delivery of the course was as effective as or more effective than in-class courses and preferred online delivery in the future. Approximately $75 \%$ of undergraduate students indicated that the online delivery of the courses was as effective as or more effective than a traditional course. However, unlike the students in the graduate course, more than one-half of combined students in the two undergraduate courses indicated that they would prefer to take an in-class course versus an online course in the future. 
The authors concluded that the online delivery appeared be an effective alternative to an in-class course but also advised that the fully online delivery was more appropriate for the graduate course than with the two undergraduate courses. Our final study in this section looks at the use of online homework managers and clickers which are devices that allow students to respond to in-class questions and communicate those answers to the instructor. Both methods could benefit in-class instruction. Homework managers may provide benefits to both students and instructors. Students complete homework in a convenient format, receive feedback on their answers and performance, and often may receive hints and access to textbook sections. Instructors rely upon the system to grade homework and track grades.

Clickers, or classroom response devices, increase student classroom engagement and provide instant feedback to students. The feedback can be useful both as teaching a concept directly and through showing students in which areas they need to improve. Clicker feedback can also alert instructors to content areas that are not sufficiently understood by students. Wooley (2015) examined the use of both methods and concluded that students perceive the online homework manager to be more helpful than other tools in preparing for tests. However, the use of the online homework manager does not actually improve test performance. The higher use by some students of clickers on inclass courses help explain student test performance. This may be because using the clickers appears to proxy for both class attendance as well as class preparation.

The transmission channels and methods used by the sender will contribute to the level of the active participation by the student in the receipt and the process of decoding the information. The process of decoding the information will also be subject to various attributes and attitudes of the student. The studies discussed indicate that evidence of the ability of the student is a good guide to their performance in both in-class and online courses. As most of the literature is US based, the GPA is usually used as a measure (Huh, Jin, Lee and Sehwan, 2009) although some studies have used prior accounting knowledge as a measure. The evidence available suggests that it is the student with prior ability who is best able to benefit from online courses.

Tan and Lazwad (2008) surveyed business students enrolled in an introductory accounting course in a New Zealand University. The results show that three factors (personal, referents, and control) are determinants of students' intention to major in accounting or other business disciplines. Further analysis revealed that the students' major intentions are influenced by important referents' perceptions. In particular, parents appear to have a strong influence on students' intentions to major in accounting. Comparisons of differential personal perceptions by accounting and non-accounting majors revealed that accounting majors hold positive perceptions of some of the qualities of the study of accounting and the accounting profession.

Lucas and Meyer (2005) conducted a survey of 1211 students taking introductory accounting in five UK universities. The findings show that there are variations in conception and approach to learning between students who specialise in accounting and those who do not, and between male and female accounting students. The differences in learning are attributable to students who specialise in accounting. The research also found that female students perform better in examinations than male students. It is emphasised that these conclusions are from comparison of groups of students and there will be individuals within those groups who outperform irrespective of the gender or accounting aspirations.

Teixeria, Gomes and Borges (2015) have also identified the better performance of female students in a study of student performance in introductory accounting courses. The results of that research suggest that accounting students seem to value the study of accounting more than non-accounting students, and that female students appear more prepared to accept higher education requirements and responsibilities than the male students.

It is generally accepted that a student's cultural background can affect learning. This can be a fundamental quality of a particular society but also arise because of previous accounting regulations. A French study (Bonnier, Demerens, Hossfieldand Le Manh, 2013) found that the adoption of IFRS in the EU required teaching to change from a rules based approach reliant on a bookkeeping-oriented course to one in which students have to define and analyse various transactions using broader economic and financial concepts.

Several researches have concluded that students with English as their first language performed better than those with a first language other than English. Tan and Lazwad (2008) found that, although international students met language entry requirements, their language skills impacted negatively on their performance. It was also claimed that some international students were not used to the learning style which requires them to demonstrate their understanding of the subject matter rather than regurgitate the material studied. This difficulty in understanding the application of the concepts instead of merely remembering definitions has also been observed with English speaking students (Husseyand Ong, 2019). Prior accounting knowledge may improve examination performance. This is usually measured by the student having already undertaken some accounting courses and is confirmed by the research undertaken for this document. 
However, interviewing of students taking an introductory course indicates that those with work experience in a business setting may also perform well on an introductory accounting course although there has been no prior formal study (Husseyand Ong, 2019).

In the literature, and practice, there is the underlying opinion that part of the learning issue is the lack of student effort. Effort is not only measured in time but it is the quality of the effort termed "deliberate practice" that is important (Wong, Sum, Chan and Wong, 2019). Students identified as having higher levels of hope, optimism and clearly defined goals could lead the learning community resulting in increasing retention and motivation.

\section{Evaluating transmission methods}

Both in-class and online assessment methods provide feedback both to lecturers and the students. In recent years, there has been a growing trend to use technology for assessing students' knowledge. The method provides many advantages, particularly for Multiple Choice Questions where there are significant savings in lecturer's time. Computer-aided assessment (CAA) offers an option for "sustainable assessment" and one study (Marriott and Lau 2008) examined a series of on-line summative assessments that were introduced into a first-year financial accounting course. The results from interviews indicated that students perceived a beneficial impact on learning, motivation, and engagement.

Aisbittand Sangster (2005) looked at the first year of an asynchronous internet-based on-line assessment system on an introductory accounting course. The findings showed a positive correlation between student performance in the on-line assessments and in their final examination. It should not be concluded from this that the assessment system is better than an in-class method as no comparison was made. It does provide confidence in using such a method as the online performance is a predictor of final performance.

With many studies, the results show that students actively engaged in any assessment system tend to perform better in the final examinations. One study (Mo and King 2015) investigated the effect of time spent and online behaviour (e.g., procrastinators vs. non-procrastinators) on students' performance in online assignments and overall course grade. The conclusion was that a web-based learning system could be used for instructors to identify students in need of assistance in the learning process. The active engagement of students was also observed by Peng (2009). The conclusion from that study was that individual intrinsic motivation and computer efficacy are important factors in determining students' active engagement with an online assessment method.

\section{A Conceptual Framework}

To study the complete learning process from the encoding and transmission of information to the decoding of information by students and the subsequent assessment and feedback requires a structured research process. To draw the various elements together we have developed a conceptual framework for conducting research in this area. This shows there is a sender of information who may or may not have authority for the content but probably has significant involvement with encoding and the method for transmitting the information.

Those processes are subject to several affecting variables. The recipients of the information, the students, also will have a decoding process that is subject to affecting variables. Finally, there is an assessment process and feedback on the performance achieved by the students.

In reviewing the research conducted to date using a conceptual framework as the structure, three very important issues arise. First, little has been written on the strength and weaknesses of textbooks. Secondly, the majority of the research is conducted with students and there is limited insight into the role and contribution of lecturers in the communication process. The work by Abbott and Palatnik (2018) concluded that accounting professors must adapt their teaching methods to help students to meet professional demands, such as critical thinking skills and ability to handle a complex global business environment. Thirdly, and most importantly, the majority of the studies are isolated. Although they may be referenced to similar studies, there are rarely direct comparisons made between different institutions, countries orsituations. If we are to improve accounting education, research is required which is more expansive. We suggest that a comprehensive study should be made with several universities for at least two years. The sequence of the project is as follows.

1. Initial discussions by Skype or email with exchange of information on such issues as the textbook used, dates of semesters, number of students, syllabus for the course, any relevant university regulations such as those applied by an internal ethics committee. Agreement to be reached on the nature of the student cohort to be studied.

2. Exchange of materials and discussions on the syllabus at the institution as well as the admission requirements for students.

3. Research into the approach and techniques adopted by the lecturers giving the course. This would include the use of Virtual Learning Environments. 
4. Exchange of material to be used on the course and discussion on the design and use of questionnaires and interviews. It seems sensible that the students would be studying the same topic and this would be the focus of the investigation. We would suggest accounting concepts.

5. Limited number of interviews with students to assess the structure and content of the questionnaire to be used.

6. Distribution of questionnaire. It needs to be decided whether a paper questionnaire will be completed or whether an electronic one. Our experience with student questionnaires is that it is only students who attend lectures complete them thus distorting conclusions. Investigations should be conducted into the use of electronic questionnaires embedded in the course material.

7. The studies should be conducted at least in the following year with the new group of students taking the same courses.

Although the conduct of such a large study would present difficulties and require careful planning, the findings would advance our knowledge of accounting education. Instead of individual and isolated studies, it would be possible to conduct institutional comparisons and draw conclusions that are not possible with our present approach to accounting education research.

\section{Conclusions}

Understanding and improving the process of accounting education is important. Although there have been many studies, they have only focussed on one part of the communication process, that is the achievement of the students. Although such research has given many insights, it provides only partial understanding of the entire process. If we are to improve our knowledge of accounting education, we need a more expansive approach. We have drawn from previous research to suggest a comprehensive approach based on a conceptual framework.

Our framework is based on the literature on communication theory and we suggest that it is used as a basis for a significant research project. We have set out the procedure to be followed in conducting the research. This would be a major project but we believe that if we are going to make progress in improving accounting education, we can only do so with a comprehensive study based on the conceptual framework we have put forward.

\section{References}

Abbott,J.I.andPalatnik B.P.A.(2018). Students' perceptions of their first accounting class: implications for instructors. Accounting Education, 27(1), 72 - 93.https://doi.org/10.1080/09639284.2017.1381032.

Aisbitt, S. and Sangster, A. (2005).Using internet-based on-line assessment: A case study.Accounting Education. December 2005, 14(4), 383-394.

American Accounting Association (1972). Report of the Committee on Application of Learning and Communications Theories to Accounting Instruction. Committee Reports: Supplement to Volume XLVII of The Accounting Review (1972). 267-292.

Baker, P.S.(2016). An Experiment with the Old and the New: Online Practice versus Practice by Hand in Learning GAAP for Pension Accounting. Journal of Accounting and Finance. 16(3).78-87.

Bedford, N. M.and Baladouni, V.A.(2002).Communications Theory to Accountancy. Ebsco Publishing. 650-659.

Berlo, D. K.(1960) The Process of Communication.New York: Holt, Rinehartand Winston.

Bonnier, C.,Demerens, F,Hossfeld, C. and Le Manh, A.(2013)A French Experience of an IFRS Transition.Issues in Accounting Education. May2013, 28(2), p.221-234. DOI: 10.2308/iace-50376

Braun, K.W. and Sellers R.D. (2012).Usinga "Daily Motivational Quiz" to IncreaseStudent Preparation, Attendance, andParticipation. Issues in Accounting Education. 27(1). DOI: 10.2308/iace-10219. 267-279.

Bunker, R. and Harris, D.(2014).A Comparison of AACSB-Accounting-Accredited and Business-Accredited Institutions, Using the CPA Examination as a Post-Curriculum Assessment. Journal of Accounting and Finance. 14 (6). 127-32.

Chen, C.J., Jones, K.T. and Moreland K.A. (2013).Online Accounting Education versus In-ClassDelivery: Does Course Level Matter? Issues in Accounting Education. 28(1). DOI: 10.2308/iace-503032013. 1-16.

Du, C. (2015).The Effect of Cooperative Learning on Students' Attitude in First-YearPrinciples of Accounting Course. Business Education Innovation Journal. 7(2).107-116. December.

Ferguson, J., Collison, D., Power, D., and Stevenson, L. (2010). Introductory financial Accounting Students' ViewsofCourseTexts. International Journal of Management Education. 9(1): 81-90.

Grimm, S. D. (2015).Learning Logs: Incorporating Writing-to-Learn Assignments into Accounting Courses. Issues in Accounting Education. 30(2).79-104. DOI: 10.2308/iace-50980. 79-104.

Huh, S.Jin, J. Lee, K.J. Sehwan, Y. (2009). Differential effects of student characteristics on performance online vis-à-vis offline accounting courses. Academy of Educational Leadership Journal. 13(2).83-91.

Hussey, R. and Ong, A. (2019).Factors Affecting Students' Performance in First-Year Accounting. 17th Annual International Conference on Accounting. ATINER Conference Paper Series No: ACC2019-2663. Athens. 
Kirstein, M.and Kunz, R.(2015).Student-centred approach to teaching large classes: friend or foe?Meditari Accountancy Research, Emerald Group Publishing.23(2), 222-246. August. doi:10.1108/MEDAR-062013-0025.

Lopez-Gavira, R.and Omoteso, K.(2013). Perceptions of the Usefulness of VirtualLearning Environments in AccountingEducation: A Comparative Evaluation ofUndergraduate Accounting Students inSpain and England. Accounting Education: an international journal, 22(5). 445-466. http://dx.doi.org/10.1080/09639284.2013.814476.

Lucas, U. and Meyer, J. (2005). Towards a mapping of the student world': the identification of variation in students' conceptions of, and motivations to learn, introductory accounting.British Accounting Review. June. 37(2).177-204. 28p. DOI: 10.1016/j.bar.2004.10.002.

Marriott, P. and Lau, A. (2008). The use of on-line summative assessment in an undergraduate financial accounting course.Journal of Accounting Education.26(2),73-90.

Mo, S. and King, G.H. (2015). The clock is ticking- an analysis of time spent on online assessments. Academy of Educational Leadership Journal, 19(2), 129-134.

Morgan, A.R. (2015). Building a Model to Measure the Impact of an Online Homework Manager on Student Learning in Accounting Courses.Business Education Innovation (BEI) Journal. 67-72.

Peng J.C.(2009).Using an online homework system to submit accounting homework: role and cognitive need, computer efficacy and perception. Journal of Education for Business May/June. 263-8.

Perera, L. and Richardson, P. (2010). Students' Use of Online Academic Resources within a Course Web Site and Its Relationship with Their Course Performance: An Exploratory Study.Accounting Education: An international journal. 19(6), 587-600, December.

Sargent, C.S.,Borthick, A.F. and Lederberg, A.R. (2011). Improving Retention for Principles ofAccounting Students: Ultra-Short Online Tutorials for Motivating Effort and Improving Performance. Issues in Accounting Education 26(4).657-679.

Shannon, C.E. and Weaver, W.(1949).TheMathematical Theory of Communication.Urbana: The University of Illinois Press.

Tan, L. M. and Lazwad, F. (2008).Impact of prior content andmeta-cognitive knowledge onstudents' performance in an introductory accounting course. Pacific Accounting Review. 20(1).63-74. www.emeraldinsight.com/0114-0582.htm63-74.

Teixeira,C.,Gomes, D. and Borges, J. (2015).Introductory Accounting Students' Motives,Expectations and Preparedness for Higher Education: Some Portuguese Evidence.Accounting Education. 24(2):123-145.

Watters,M. P. and Robertson, P.J. (2009). Online Delivery of Accounting courses. Students' perceptions. Academy of Educational Leadership Journal. 13(3), 51-57.

Wong, H. Sum, C. Chan, S. and Wong, R. (2019).Effect of Deliberate Practice and Previous Knowledgeon Academic Performance.International Journal of Business \& Information.25-46.

DOI: 10.6702/ijbi.201903_14(1).0002pp25-46.

Woolley D. J. (2015). Which helps accounting students learn: traditional homework, onlinehomework or clickers? Academy of Educational Leadership Journal,19(3), 337-343. 
Accounting Education -conceptual framework

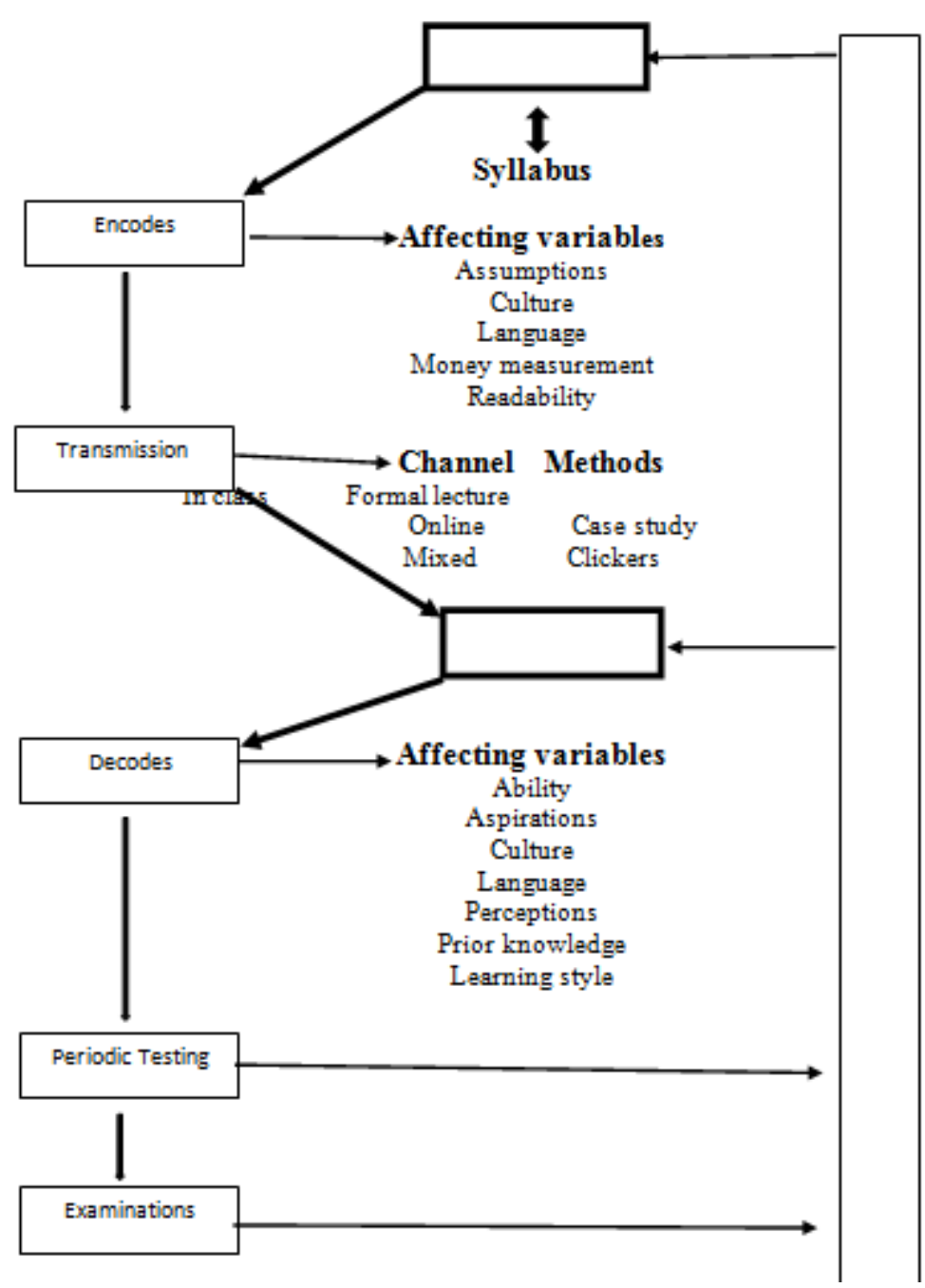

